Социально-экологические изменения и изменения в области здравоохранения в результате осуществления горнодобывающих проектов в Баркарена-ПА: развитие и его противоречия в Амазонии, Бразилия

\title{
ОРИГИНАЛЬНАЯ СТАТЬЯ
}

SOUZA, Keulle Oliveira da ${ }^{[1]}$, MOREIRA, Elisângela Claudia de Medeiros ${ }^{[2]}$, DIAS, Cláudio Gellis de Mattos ${ }^{[3]}$, FECURY, Amanda Alves ${ }^{[4]}$, NETO, Manoel Samuel da Cruz ${ }^{[5]}$, DENDASCK, Carla Viana ${ }^{[6]}$, PIRES, Yomara Pinheiro ${ }^{[7]}$, BAHIA, Mirleide Chaar ${ }^{[8]}$, FERNANDES, Roseane do Socorro da Silva Matos ${ }^{[9]}$, OLIVEIRA, Euzébio de ${ }^{[10]}$

SOUZA, Keulle Oliveira da. Et al. Социально-экологические изменения и изменения в области здравоохранения в результате осуществления горнодобывающих проектов в Баркарена-ПА: развитие и его противоречия в Амазонии, Бразилия. Revista Científica Multidisciplinar Núcleo do Conhecimento. 04 год, Эд. 12, Vol. 08, стр. 29-39. Декабрь 2019
года .
ISSN :
$2448-0959$,
Ссылка
доступа:

https://www.nucleodoconhecimento.com.br/окружающая-среда/экологические-изменения, DOI: $\quad$ 10.32749/nucleodoconhecimento.com.br/oкружающая-среда/экологическиеизменения

\section{Contents}

- PEЗЮME

- 1. ВВЕДЕНИЕ

- 2. МЕТОДОЛОГИЯ

- 3. РЕЗУЛЬТАТЫ И ОБСУЖДЕНИЕ

- 4. ЗАКЛЮЧИТЕЛЬНЫЕ СООБРАЖЕНИЯ

- сСЫЛКИ

\section{PEЗЮME}

Столкнувшись с экологическими проблемами и деятельностью горнодобывающей промышленности, важно проанализировать взаимосвязь между социальными и экологическими проблемами и вопросами здравоохранения и горнодобывающей деятельности и их прямой связью с развитием, особенно экономической. Нынешняя работа была направлена на оценку социально-экологических изменений и изменений в области здравоохранения в результате осуществления крупных горнодобывающих 
Социально-экологические изменения и изменения в области здравоохранения в результате осуществления горнодобывающих проектов в Баркарена-ПА: развитие и его противоречия в Амазонии, Бразилия проектов в Баркарена-ПА, контекстуализации развития и его противоречий в бразильской Амазонии. Для этого использовались библиографические исследования, о литературе, опубликованной в книгах, научных и документальных статьях, связанных с изучаемой темой. Было установлено, что Бразилия представляет собой один из самых больших потенциалов минеральных ресурсов на планете, с примерно 55 видов полезных ископаемых, которые могут быть использованы для экономических целей разведки. С другой стороны, помимо содействия укреплению региональной и национальной экономики, а также увеличению числа рабочих мест и увеличению доходов местного населения, как это имеет место в случае муниципалитета Баркарена-ПА, этот регион страдает от последовательных социально-экологических и медико-санитарной деятельности, которая развивается в регионе. Окрестности крупных горнодобывающих проектов населены семьями, которые, поскольку их осуществление имеют свой образ жизни, их экономика, их здоровье и их социальнокультурной организации влияние, в результате этой деятельности и последовательных экологических последствий, которые происходят на сайте. Учитывая все, что было проанализировано, можно сделать вывод, что, поскольку это ускоренная модель экономического развития, и часто не должным образом спланированы, не принимая во внимание особенности бразильской Амазонии, он в конечном итоге генерации многочисленных экологических, социальных последствий, которые даже непосредственно отражают серьезные проблемы со здоровьем местного населения. Таким образом, необходимо срочно переосмыслить эту форму осуществления проектов по разведке полезных ископаемых в регионе Амазонки, как это имеет место в городе Баркарена, поскольку крупные социально-экологические катастрофы все еще могут произойти.

Ключевые слова: Изменения, социально-экологические, здравоохранения, горнодобывающей промышленности, Амазонки.

\section{1. ВВЕДЕНИЕ}

Орес существует с самого начала мира. Они являются минеральными образованиями, которые составляют естественно и экономически интересны для их добычи. На Земле, железо является тот, который появляется в наибольшем изобилии производства в 
Социально-экологические изменения и изменения в области здравоохранения в результате осуществления горнодобывающих проектов в Баркарена-ПА: развитие и его противоречия в Амазонии, Бразилия коре. В списке руд, имеющих большое значение для нашей жизни, у нас также есть медь, золото, алюминий и уголь. Этот список огромен, и они имеют важное значение для модели разработки, развернутой на земном шаре. Без них все было бы так же, как мы видим сегодня. И все больше и больше будет необходимо, потому что чем больше технологическое развитие, тем больше спрос на эти продукты (OLIVEIRA, 2019; SIMINERAI, 2019).

Бразилия представляет собой один из самых больших потенциалов минеральных ресурсов на планете, с примерно 55 видов минералов, которые могут быть использованы для целей разведки, таких как железо, медь, золото, марганец, ниобий, среди других. Запасы железа в Бразилии в среднем составляют 45,7\% и составляют 17\% мировых запасов. В штате Пара, Северная Бразилия, «минеральная промышленность создает 266000 прямых и косвенных рабочих мест в местной производственной цепочке и составляет $20 \%$ валового внутреннего продукта Бразилии» (SIMINERAI, 2019).

Как известно, эти отрасли реализуют в регионе гигантские работы и сооружения, такие как этот НПЗ (рисунок 1), установленный в городе Баркарена-ПА, для переработки полезных ископаемых, добываемых из амазонских почв.

Рисунок 1: Нефтеперерабатывающий завод добываемых минералов, Баркарена-ПА. Источник: Tarso Sarraf, O LIBERAl, 2017. 
Социально-экологические изменения и изменения в области здравоохранения в результате осуществления горнодобывающих проектов в Баркарена-ПА: развитие и его противоречия в Амазонии, Бразилия

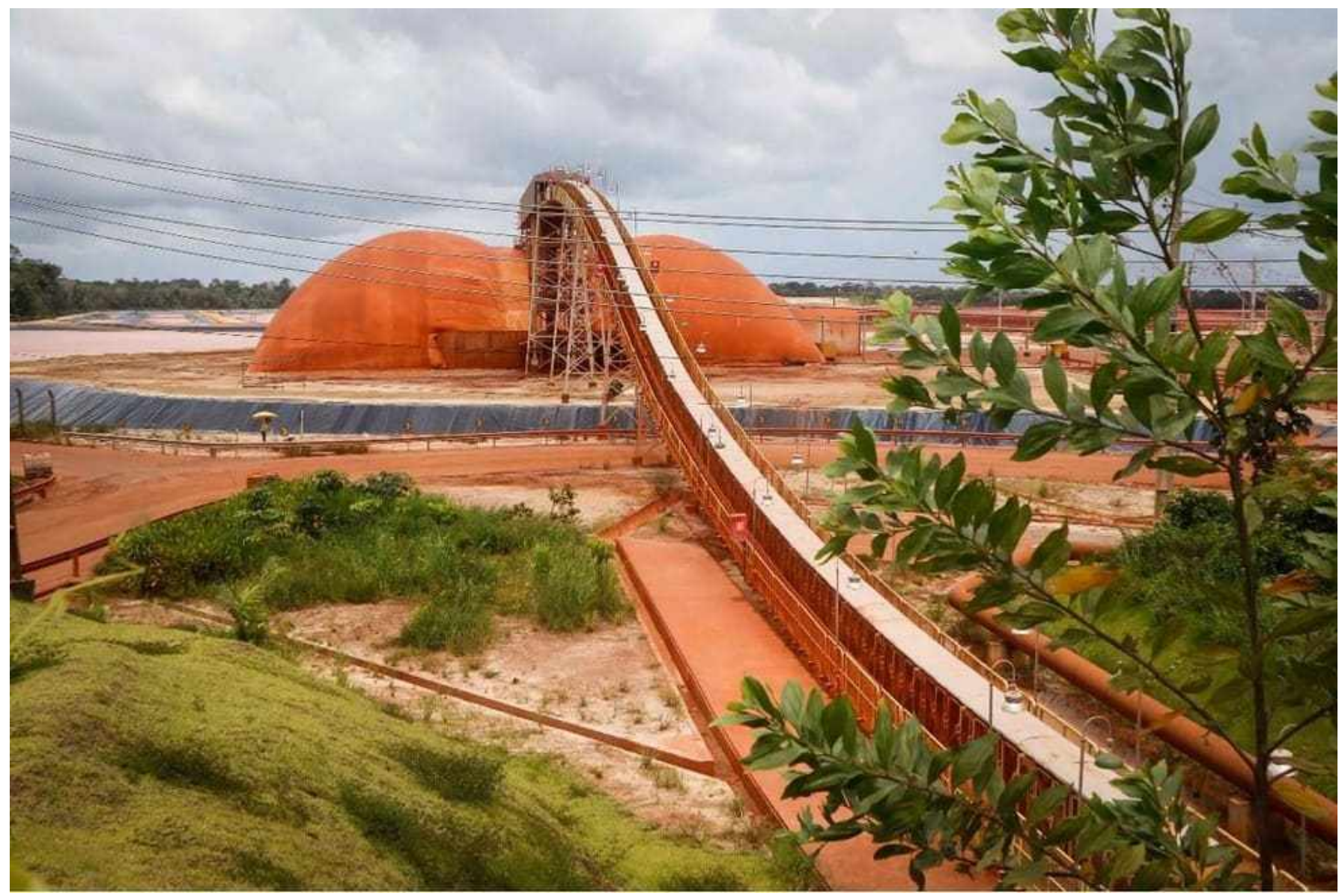

Источник: Данные поиска.

С другой стороны, помимо содействия укреплению региональной и национальной экономики, а также созданию рабочих мест и увеличению доходов местного населения, муниципалитет Баркарена-Па страдает от последовательных социальноэкологических и медико-экологических последствий в связи с горнодобывающей деятельностью, разработанной в регионе. Окрестности крупных горнодобывающих проектов населены семьями, которые с момента их осуществления имеют свой образ жизни, свою экономику, свое здоровье и свою социально-культурную организацию, непосредственно пострадавшие от многочисленных социально-экологических катастроф, которые произошли на этом объекте (NASCIMENTO; HAZEU, 2015).

За последние двадцать лет были зарегистрированы бокситы, каолин, загрязнение рек, речные и водные колодцы, которые снабжают семьи, непосредственно затрагивая жизнь местных общин, нанося неисчислимый ущерб здоровью жителей и окружающей 
Социально-экологические изменения и изменения в области здравоохранения в результате осуществления горнодобывающих проектов в Баркарена-ПА: развитие и его противоречия в Амазонии, Бразилия

среде, в которой они живут (MAIA; MARIN, 2014).

Масштабы и сложность понимания этого явления делают необходимым поиск ссылок в области социальных наук и здравоохранения, учитывая, что окружающая среда и здоровье являются неотделимыми областями человека, непосредственно связанными с их существованием и потрененностью на Земле. Однако окружающая среда в ее высокой сложности не нуждается в том, чтобы человек оставался и существовал. В этих условиях «размышления направляются для того, чтобы понять, как окружающая среда вмешивается в здоровье человека и как люди вмешиваются в баланс окружающей среды», то есть крайне важно знать причины, выводы и воздействия человека на окружающую среду (MACEDO, 2019, р. 20).

С учетом вышесказанного необходимо лучше понять изменения или социальноэкологическое воздействие и на здоровье местных жителей в результате осуществления горнодобывающих проектов в Баркарена-Па с целью понять, как происходят и продолжаются эти процессы установки и эксплуатации этих крупных предприятий, с тем чтобы охарактеризовать возможный ущерб окружающей среде и здоровью местных и близлежащих жителей.

Таким образом, нынешняя работа была направлена на оценку социальноэкологических изменений и изменений в области здравоохранения в результате осуществления крупных горнодобывающих проектов в Баркарена-ПА, контекстуализации развития и его противоречий в бразильской Амазонии в результате деятельности этих предприятий.

\section{2. МЕТОДОЛОГИЯ}

Настоящая работа выполнена посредством описательно-аналитического и исследовательского исследования, разработанного на основе библиографических исследований литературы, опубликованной в книгах, научных и документальных статьях, относящихся к изучаемой теме. Что касается подхода, то он качественный, он направлен на анализ реальности темы, выделяя основных авторов, которые обсуждают основные проекты в бразильском регионе Амазонки, особенно в Баркарена-ПА, 
Социально-экологические изменения и изменения в области здравоохранения в результате осуществления горнодобывающих проектов в Баркарена-ПА: развитие и его противоречия в

Амазонии, Бразилия

муниципалитете, граничащем с Беленом, Понта-де-Педрас и Абететуба. все принадлежит государству из Пара.

Он носит описательно-аналитический характер, поскольку был направлен на классификацию, описание, объяснение и прояснение представленной проблемы. Это также исследовательский, поскольку он направлен на исследование, анализ и описание основных идей авторов через исследуемую информацию по рассматриваемой теме.

\section{3. РЕЗУЛЬТАТЫ И ОБСУЖДЕНИЕ}

Реализация крупных горнодобывающих проектов в бразильском регионе Амазонки вызвала много споров с течением времени. В начале 20 века открытие предприятия Henry Ford, известной Ford Motor Company, означало приход современных компаний в штат Пара, породив большие надежды на начало промышленного и экономического развития региона. В результате реализации этого грандиозного исследовательского проекта возник город Belterra и Vila, широко известный как Fordlândia, также представляющий модель разведки, основанную на добыче каучука, для удовлетворения международного спроса на автомобили (CANTO, 2015).

В более широком смысле и в результате установки крупных промышленных проектов в регионе социально-экологические конфликты, существующие сегодня в бразильской Амазонии, представляют собой сложные процессы, включающие различные темы и многочисленные интересы, от экономических до экологических. Для Canto (2016 г., стр. 89) «территориальноизация крупных компаний, иностранных или нет, была эпицентром социально-экологических конфликтов в самых разных уголках Амазонки». Напряженность различного происхождения, связанная с добычей полезных ископаемых, лесозаготовками, речными проблемами, сельскохозяйственными и пастбищным конфликтами, рыболовными конфликтами, демаркацией земель коренных народов и многими другими.

В контексте разведки полезных ископаемых с 70-х годов в штате Пара были накоерды объекты крупных предприятий. В качестве ответвления проекта Гранд-Карахес (PGC), 
Социально-экологические изменения и изменения в области здравоохранения в результате осуществления горнодобывающих проектов в Баркарена-ПА: развитие и его противоречия в Амазонии, Бразилия компании сосредоточены на производстве глинозема и первичного алюминия были реализованы в регионе. Бразильская компания «Альбрас» поселилась в муниципалитете Баркарена, Пара, начав свою деятельность в 1985 году (MONTEIRO, 2005; MACÊDO, 2019).

Баркарена был городом, выбранным для размещения крупных промышленных проектов, из-за его стратегического положения, чтобы служить европейским и североамериканным рынкам, во-первых: для наличия дешевой рабочей силы, крайне необходимой для некоторых рабочих мест и из-за его близости к столице штата Пара, города Белем, тем самым облегчая деятельность компании (NAHUM, 2011; SILVA, HAZEU, 2019). (Рисунок 2).

Рисунок 2: Расположение муниципалитета Баркарена-ПА.

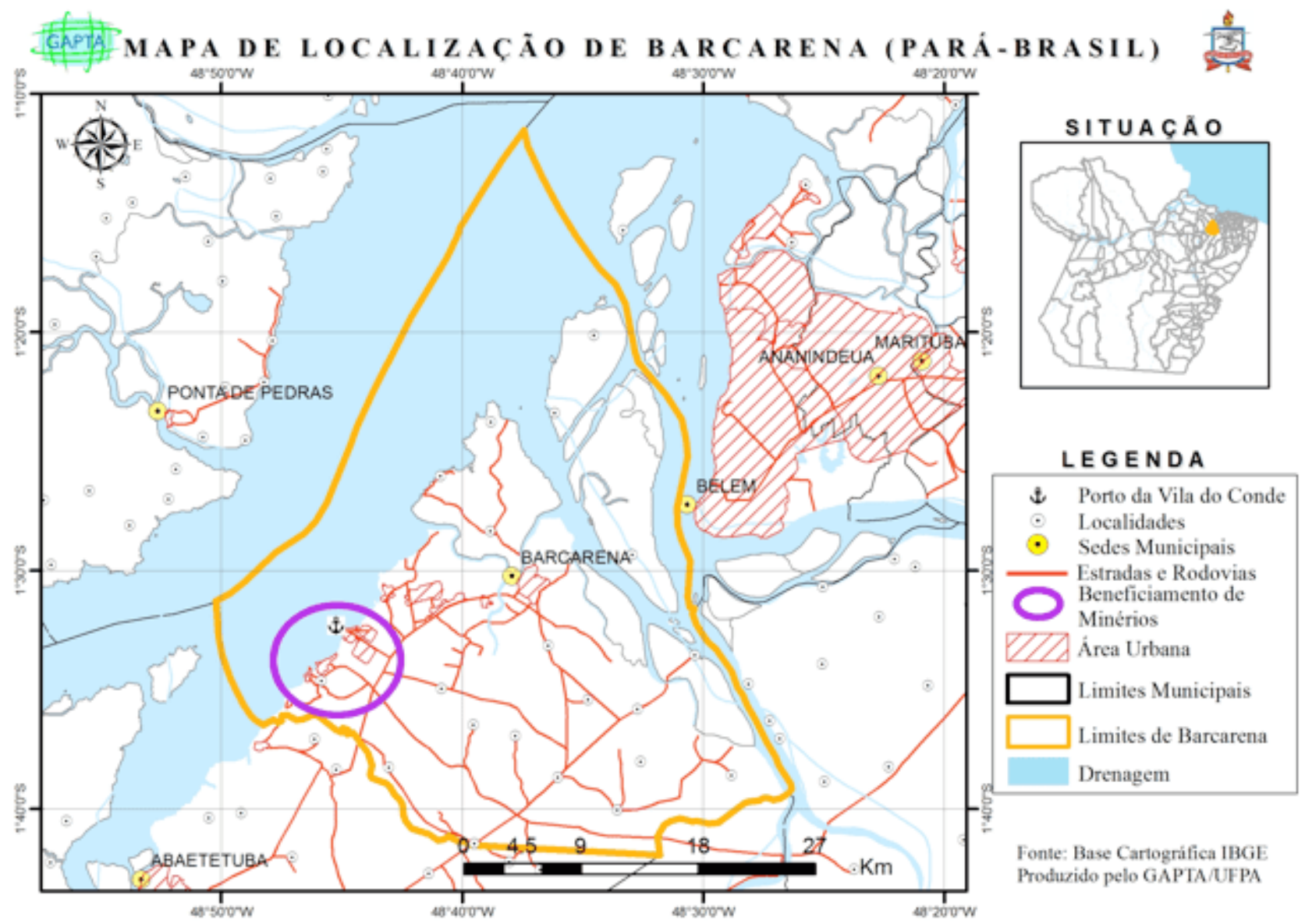

Источник: Ibge Cartographic Base- Произведено GAPTA/UFPA, 2017. 
Социально-экологические изменения и изменения в области здравоохранения в результате осуществления горнодобывающих проектов в Баркарена-ПА: развитие и его противоречия в Амазонии, Бразилия

Осуществление крупных промышленных проектов в области развития в Баркарене было переплетено с серией процессов перемещения, чаще всего против вкуса, традиционных общин, проживающих в регионе. Marin (2017), подчеркивает, что существует очевидная напряженность между, конкретные территории, которые составили муниципалитет до 1970-х годов, и крупные предприятия, установленные там, в связи с введением формы ускоренного развития, в основном не очень хорошо спланированы, который был взят промышленной концепции, особенно с 1980 года.

Формирование государственной политики, способной в том числе крупных проектов, и в то же время посредничество в отношениях с традиционным населением Barcarena имеет основополагающее и стратегическое значение, в контексте отмечен убеждение местного населения, идея прогресса для муниципалитета. Для (CARMO; COSTA, 2016, стр. 291) «в 1980-х годах внимание государственной политики обратилось к муниципалитету, чтобы оно служило интересам государства и внешним интересам», получив крупный проект под названием Промышленный комплекс Алунорта.

По словам Maia и Marin (2018), компании Norsk Hydro (Алунорте и Альбрас), Имерис Рио Капим Каулим, Пара Пигментос, Буритама, Текоп, Воторантин и Усик постоянно преобразуют муниципалитет Баркарена, превращая регион в месторождение промышленных отходов, вытесняя леса и вытесняя целые люди и общины, чтобы построить больше, тем самым создавая серьезный ущерб окружающей среде, усугубляя социальные проблемы и тем самым порождая серьезные проблемы со здоровьем для этих групп населения.

Среди наиболее эксплуатируемых минералов в регионе Баркарена, алюминий $(A L)$ может быть выделен, который критикуется со стороны хорошей части врачей. Они засовыляют, что отравление алюминием все чаще изучается и связано с запорами, спазмами в животе, анорексией, тошнотой, усталостью, изменениями в метаболизме кальция (рахитами), неврологическими изменениями с тяжелым повреждением тканей мозга. В детстве это может вызвать гиперактивность и расстройства обучения. Многочисленные исследования считают, что Аль играет чрезвычайно важную роль в ухудшении болезни Альцгеймера (раннее слабоумие). Избыток Al препятствует усвоению селена и фосфора. Кислые продукты увеличивают поглощение Al и увеличивают высвобождение аль-горшков, сделанных с этим минералом (PRADO FILHO, 
Социально-экологические изменения и изменения в области здравоохранения в результате осуществления горнодобывающих проектов в Баркарена-ПА: развитие и его противоречия в

Амазонии, Бразилия

2010).

По мнению Salvador (2013), необходимо и безотлагательно энергичные действия наших властей, как для обеспечения населения региона, в том числе самих рабочих полные и прозрачные лабораторные испытания, без махинаций, для диагностики заболеваний в результате загрязнения тяжелыми материалами, вредными для здоровья человека, используемых в эксплуатации алюминиевой цепи, сохраняя здоровье населения этих граждан.

Каждый больной работник, по-прежнему с продолжением и или инвалидности на работу, должны иметь гарантированное их право на серьезные и истинные диагностические обследования, направленные на получение социальной помощи, гарантированной законом для всех работников с продолжением и или профессиональной инвалидности, которая во многих случаях было отказано, либо недостатки практики уведомлений, или практика, проведенная INSS по сокращению своих расходов с предоставлением пособий по социальному обеспечению, вместо того, чтобы морализаторские проверки, чтобы защитное законодательство человеческого труда, с безопасностью, здоровьем и достоинством выполняется, без известных пороков системы (SALVADOR, 2013).

\section{4. ЗАКЛЮЧИТЕЛЬНЫЕ СООБРАЖЕНИЯ}

В этой противоречивой логике развития отмечается, что глобальный спор о природных ресурсах бразильского региона Амазонки делает спор о контроле над своей территорией решающим в геополитическом контексте Амазонки. Однако эта модель сильно контрастирует с населением, экономической, культурной, политической и социальной динамикой региона.

И поскольку это ускоренная модель экономического развития, и зачастую не планируется должным образом, с учетом особенностей бразильской Амазонии, она в конечном итоге генерации многочисленных экологических и социальных последствий, которые даже непосредственно отражают серьезные проблемы со здоровьем местного населения, как это наблюдается в данном обзоре. 
Социально-экологические изменения и изменения в области здравоохранения в результате осуществления горнодобывающих проектов в Баркарена-ПА: развитие и его противоречия в

Амазонии, Бразилия

Несмотря на все, что было проанализировано, поэтому необходимо срочно пересмотреть эту форму осуществления проектов по разведке полезных ископаемых в районе Амазонки в Бразилии, поскольку крупные социально-экологические катастрофы все еще могут произойти, затрагивающие многие человеческие жизни.

\section{ССЫЛКИ}

CANTO, O. Mineração na Amazônia: assimetria, território e conflito socioambiental. NUMA, UFPA. 2016.

CARMO, M.; COSTA, S. Os paradoxos entre os urbanos no município de Barcarena, Pará. Disponível em: https://periodicos.pucpr.br/index.php/Urbe/article/view/22077/21187. Acesso em 07 de Outubro de 2019.

MACEDO, J. Desastre Socioambiental em Barcarena: a percepção dos moradores de Vila do Conde sobre o naufrágio Haidar. Dissertação de mestrado. Programa de Pós-Graduação em Estudos Antrópicos na Amazônia. UFPA/Castanhal. 126 folhas. 2019.

MAIA, R. Territorialidades específicas em Barcarena confrontadas com projetos de "desenvolvimento". 2017. 321 f. Tese (Doutorado) - Universidade Federal do Pará, Programa de Pós-Graduação em Desenvolvimento Sustentável do Trópico Úmido. Núcleo de Altos Estudos Amazônicos, Belém, 2017.

MAIA, R.; MARIN, R. A arte da resistência de comunidades tradicionais em Barcarena (Pará) face à ordem e progresso. Papers do 38을 Encontro da ANPOCS, GT07 - Conflitos ambientais, Estado e ideologia do desenvolvimento: mediação e luta por direitos. Minas gerais, out. 2014.

MAIA, R.; MARIN, R. Gênero nas ações e resistências ao modelo de desenvolvimento imposto em Barcarena, Pará. Cad. Pagu. n.52, Nov. 2018. ISSN 0104-8333. Dossiê Desenvolvimento, Poder, Gênero e Feminismo.

MONTEIRO, M. A. Meio século de mineração industrial na Amazônia e suas implicações para o desenvolvimento regional. Coleção Estudos Avançados, Ed. 19 (53), 2005. 
Социально-экологические изменения и изменения в области здравоохранения в результате осуществления горнодобывающих проектов в Баркарена-ПА: развитие и его противоречия в Амазонии, Бразилия NASCIMENTO, N. S. F.; HAZEU, M. T. Grandes empreendimentos e contradições sociais na amazônia: a degradação da vidano município de Barcarena, Pará. Argumentum, Vitória (ES), v. 7, n. 2, p. 288-301, jul/dez. 2015.

NAHUM, J. S. USOS LOCAIS DAS NORMAS GLOBAIS: implantação da lei de responsabilidade fiscal em Barcarena-Pará (local uses of the global norms: the implantation of the law of fiscal responsibility in Barcarena-Pará). Mercator, Fortaleza, v. 7, n. 13, p. p. 7 a 18, nov. 2008. ISSN 1984-2201.

NAHUM, J. S. Usos Locais das Normas Globais: implantação da Lei de Responsabilidade Fiscal em Barcarena. Mercator. Revista de Geografia da UFC. v. 07, p. 7-18, 2008a.

OLIVEIRA, B. A. A riqueza debaixo dos nossos olhos: o potencial mineral no Amazonas. Opinião Editorial Open Weather, 04, junho, 2019.

PRADO FILHO, H, R, D. A insustentabilidade da indústria do alumínio. Qualidade online. 16, novembro, 2010.

SALVADOR, L. RISCOS À SAÚDE PÚBLICA: Da gigantesca degradação ambiental produzida pela exploração da cadeia do alumínio. Asociacion Latino Americana de Abogados Laboralistas (ALAL). 28, julho, 2013.

SILVA, S.; HAZEL, M. O Complexo Industrial-portuário em Barcarena e a Saúde de Comunidades Tradicionais na Amazônia Brasileira. O Social em Questão - Ano XXII - no 44 Mai a Ago/2019.

SIMINERAL. Sindicato das Indústrias Minerais do Estado do Pará, 2019.

[1] Магистр по антропогенным исследованиям в Amazon-PPGEAA, в Федеральном университете Паре - UFPA, Кампус Кастанхал.

[2] Магистр теории и исследований поведения. Профессор Государственного университета Пара - UEPA, Белем (PA). Аспирант по тропическим болезням в Федеральном университете Паре - NMT/UFPA. 
Социально-экологические изменения и изменения в области здравоохранения в результате осуществления горнодобывающих проектов в Баркарена-ПА: развитие и его противоречия в Амазонии, Бразилия

[3] Кандидат теоретических и летных исследований. Профессор и исследователь Федерального института Амапе - IFAP.

[4] Кандидат тропических болезней. Профессор и исследователь в Федеральном университете Амапа, ар. Сотрудничающий исследователь в Центре тропической медицины UFPA (NMT-UFPA).

[5] Магистр сестринского дела. Профессор и исследователь Faculdade Brasil Амазения FIBRA.

[6] Богослов. Кандидат медицинских наук в области клинического психоанализа. Научный сотрудник Центра исследований и перспективных исследований, Сан-Паулу, SP.

${ }^{[7]}$ Кандидат электротехники. Профессор и исследователь в Федеральном университете Пара - UFPA, Кампус Кастанхал.

[8] Кандидат наук: Социально-экологическое развитие. Профессор и исследователь ядра амазонских исследований Федерального университета Паре - NAEA/UFPA.

[9] Кандидат наук в области образования. Профессор и исследователь Института медицинских наук Федерального университета Паре - ICS/UFPA.

[10] Кандидат медицинских наук /Тропические болезни. Профессор и исследователь в Федеральном университете Паре - UFPA. Сотрудничающий исследователь Центра тропической медицины - NMT/UFPA, Белем (PA), Бразилия.

Отправлено: декабрь 2019 года.

Утверждено: декабрь 2019 года. 